\title{
Behavioral Interventions for Antipsychotic Induced Appetite Changes
}

\author{
Ursula Werneke • David Taylor • \\ Thomas A. B. Sanders
}

Published online: 13 February 2013

(C) The Author(s) 2013. This article is published with open access at Springerlink.com

\begin{abstract}
Weight gain remains a well recognized yet difficult to treat adverse effect of many anti-psychotic drugs including agents of the first and second generation. The weight gain liabilities of antipsychotic drugs are partly associated with their ability to increase appetite. Most behavioral interventions for weight control remain of limited efficacy, possibly because they do not specifically target the neuroendocrine factors regulating appetite. Identifying new weight management interventions directly acting on the biochemical and neuroendocrine mechanisms of anti-psychotic induced weight gain may help to improve the efficacy of behavioral weight management programs. Such potentially specific strategies include (1) using diets which do not increase appetite despite calorie restriction; (2) countering thirst as an anticholinergic sideeffect; (3) discouraging cannabis use and (4) adding metformin to a behavioral intervention. In view of our currently
\end{abstract}

This article is part of the Topical Collection on Schizophrenia and Other Psychotic Disorders

\section{U. Werneke}

Department of Clinical Sciences, Division of Psychiatry, Umeå University, 90185 Umeå, Sweden

U. Werneke $(\bowtie)$

Department of Psychiatry, Sunderby Hospital,

97180 Luleå, Sweden

e-mail: uwerneke@gmail.com

D. Taylor

Pharmacy Department, South London and the Maudsley NHS Trust, Institute of Pharmaceutical Sciences, King's College London,

London, UK

e-mail: david.taylor@slam.nhs.uk

\section{T. A. B. Sanders}

Diabetes \& Nutritional Sciences Division, King's College London,

150 Stamford Street,

London SE1 9NH, UK

e-mail: tom.sanders@kcl.ac.uk rather limited treatment repertoire it seems timely systematically to explore such novel options.

Keywords Antipsychotics - Anticholinergic - Appetite · Cannabis · Diabetes · Diet $\cdot$ Insulin $\cdot$ Leptin $\cdot$ Ketogenic . Metabolic syndrome $\cdot$ Metformin $\cdot$ Prevention · Thirst . Weight gain - Behavioral interventions · Psychotic disorders · Psychiatry

\section{Introduction}

Weight gain remains a well recognized yet difficult to treat adverse effect of many anti-psychotic drugs. This problem is not new. It emerged with the introduction of the firstgeneration of antipsychotic drugs (FGAs) but was overshadowed by their propensity to cause extrapyramidal side effects and tardive dyskinesia. Only with the advent of second-generation antipsychotic drugs (SGAs) the perspective shifted from movement disorders toward weight gain as the dominant adverse effect. Weight gain is not just a concern per se. Cosmetically undesirable or even considered stigmatizing as it may be, the main concern about weight gain relates to the increased risk of metabolic syndrome, diabetes and cardiovascular disease which may result in a significant decrease in life expectancy. For instance, more than two thirds of people with schizophrenia die from coronary heart disease (CHD) as compared to about half of the unaffected population [1]. And more than one third of patients treated with antipsychotic drugs develop metabolic syndrome $[2 \cdot \bullet]$. Depending on age, up to $15 \%$ of patients with schizophrenia may develop type 2- diabetes mellitus and up to $70 \%$ may have elevated serum lipids $[2 \bullet \bullet]$.

The weight gain liabilities of antipsychotic drugs are partly associated with their ability to increase appetite. Yet, most behavioral interventions for weight control do not 
specifically target the control of appetite. Instead, most interventions are geared toward reduction of calorie intake through dieting, promotion of fruit and vegetable intake and calorie expenditure through exercise. However, such strategies tend to increase rather than reduce appetite.

Here we provide an overview of (1) the potential drivers of antipsychotic-induced increase in appetite and weight gain, (2) the results of commonly tried behavioral interventions in view of the underlying pathophysiology, (3) the potential of behavioral strategies specifically targeted at antipsychoticmediated pharmacodynamic and neuroendocrine effects and 4) the role of illicit substance use on appetite.

\section{Potential Drivers of Antipsychotic-Induced Weight Gain and Increased Appetite}

\section{Identifying Receptors Facilitating Weight Gain}

Of the FGAs, low-potency phenothiazines such as chlorpromazine carry the highest risk of increasing weight. Chlorpromazine may even increase the risk of metabolic syndrome and type 2- diabetes [3]. On the other hand, the risk of weight gain is relatively low with high-potency FGAs such as perphenazine, fluphenazine and haloperidol $[4 \cdot 5]$. Of the SGAs, clozapine and olanzapine are most likely to increase weight, appetite and to stimulate overeating. Both drugs also increase the risk of metabolic syndrome and type 2- diabetes. Quetiapine, risperidone, paliperidone, asenapine, iloperidone and sertindole can also increase weight but to a lesser extent. These drugs are currently not associated with an increased risk of metabolic syndrome. Ziprasidone, amisulpride and aripiprazole and possibly lurasidone belong to a third category of antipsychotic drugs in which the risk of weight gain and appetite increase tends to be low or negligible $[3,4 \bullet, 5,6]$.

Blockade of dopamine (D2 and D3), serotonin (5HT2c), muscarinic (M3) and histamine (H1) receptors have all been implicated to increase appetite [4•, 5, 7-9]. Weight gain liability seems inversely correlated to the specificity of the receptor profile of the antipsychotic drugs; the more receptors targeted, the less specific the drug and the more likely weight gain. Thus it is the non-specificity of an individual drug rather than the categorization into FAGs and SAGs that predict weight gain liability or metabolic risk [2••]. Nonetheless, even drugs antagonizing only dopamine receptors (amisulpride, pimozide, etc.) show at least some propensity for weight gain.

\section{Understanding Determinants of Appetite and Weight Gain}

Antipsychotic-induced stimulation of appetite and weight gain is multifactorial. Pharmacological, genetic, environmental and social factors as well as gender contribute $[2 \bullet \bullet, 5]$. In the absence of one clearly identifiable factor, identification of a single effective treatment becomes unlikely. Food intake is the result of finely balanced neuroendocrine factors. Some of these promote appetite and others satiety. There are short-acting factors such as ghrelin and cholecystokinin (CKK). There are also long acting factors, beyond the time frame of an individual meal, such as leptin and insulin [4•, 7, 10-18, 19•] (Table 1). All these factors act on the hypothalamus stimulating either orexogenic neurons such as neuropeptide-Y (NP-Y) and agouti-related peptide (AGrP) or anorexic neurons such as the melanocortins [19•]. Adenosine-monophosphate activated protein-kinase (AMPK), acts as a cellular energy sensor integrating many of the neuroendocrine functions to become " $a$ master regulator of eating behavior through its activity in the hypothalamus" [10]. Hypothalamic activity is under cognitive and emotional control of the brain though. Whereas the dopamine and endocannabioid system mediate the motivation to seek food, i.e.m "wanting", the opioid system mediates feelings of pleasure when eating, i.e., "liking" [15]. Dopamine antagonists can influence these systems at the hypothalamic and cortical level, but their actions are not always as might be anticipated. This makes specific targeting through behavioral interventions difficult.

For instance, antipsychotics with selective D2 and D3 receptor affinity such as aripiprazole, amisulpride and ziprasidone have a low risk of weight gain because blockade of hypothalamic D2 and D3 receptors increase reactivity to neuropeptide Y (NPY). This effect may be enhanced by 5HT2 and alpha 1adrenergic blockade [11].

At a cortical level, dopamine and endorphins stimulate the reward system. Blunting of the reward system by dopamine blockade may lead to overeating in an attempt to overcome the anhedonic effect $[4 \cdot, 20]$. Genetic variation may determine how well individual people can suppress eating [4•]. Thus, individual ability to fine-tune the reward system may explain why selective D2 and D3 receptor blockade can cause weight gain in only some people.

Insulin tends to decrease eating behavior under normal conditions but hyperinsulinemia promotes weight gain [16]. Treatment with insulin is also associated with weight gain. Hypoglycemia only occurs though if the insulin dose exceeds carbohydrate intake [21]. The concept that low blood sugar levels, yet still in the normal range, induce craving for carbohydrates due to a hyper-secretion of insulin remains controversial [19•, 22]. Regardless, the individual response to low-glycemic load diets may differ depending on ethnicity [23]. Regarding the diabetogenic risk of some antipsychotics we note that insulin secretion is under muscarinic control and blockade of muscarinic (i.e., not nicotinic) receptors may lead to a compensatory over-stimulation of insulin until it becomes down regulated [24]. Drugs with anti-muscarinic properties, such as clozapine, olanzapine, $\mathrm{N}$-desalkylquetiapine are diabetogenic. But olanzapine has 
Table 1 Some factors regulating eating behavior

\begin{tabular}{|c|c|c|}
\hline Substance & Organ of origin & Mechanism of action \\
\hline \multicolumn{3}{|l|}{ Stimulating food intake } \\
\hline NPY & HPT & $\begin{array}{l}\text { Stimulates neurons triggering eating behavior }[7,10,11] \text {. Stimulated by ghrelin. } \\
\text { Inhibited by leptin }[10,12] \text {. }\end{array}$ \\
\hline $\operatorname{AgRP}$ & HPT & $\begin{array}{l}\text { Inhibits activity of neurons stimulating melanocortin via GABA. Melanocortin } \\
\text { decrease eating behavior as outlined below [7, 10]. May } \downarrow \text { thyroid function in } \\
\text { the presence of MSH. }\end{array}$ \\
\hline \multirow[t]{2}{*}{$\mathrm{MCH}$} & \multirow[t]{2}{*}{ HPT } & Facilitates action of leptin. $\uparrow$ during fasting when leptin levels fall [12]. \\
\hline & & Projects into the cortex, the amygdala and the spinal cord. \\
\hline Orexins & HPT & $\begin{array}{l}\text { Regulates feeding behavior and the sleep wake cycle [12]. Ensures food- seeking } \\
\text { behavior after periods of fasting. Projects into the cortex, the amygdala and the } \\
\text { spinal cord [12]. }\end{array}$ \\
\hline AMPK & HPT & $\begin{array}{l}\text { Intracellular energy sensor acting on ATP concentration. Facilitates production of } \\
\text { ATP by opening catabolic and closing anabolic pathways }[10,13] \text {. If ATP } \uparrow \text {, } \\
\text { AMPK inactive leading } \downarrow \text { food intake. If ATP } \downarrow \text {, AMPK active leading to } \uparrow \text { food } \\
\text { intake }[10,13] \text {. AMPK action may differ between cell systems within the HPT and } \\
\text { between tissue types in the body [13,14]. For instance, the anti-diabetic drug } \\
\text { metformin inhibits AMPK in the HPT but stimulates it in the skeletal muscle [13]. }\end{array}$ \\
\hline \multirow[t]{2}{*}{ Ghrelin } & \multirow[t]{2}{*}{ ST } & $\begin{array}{l}\text { Short acting. } \uparrow \text { eating when the stomach is empty [10]. Stimulates AMPK, NYP and } \\
\text { AgRP and inhibits melanocortin in the HPT }[7,13,14] .\end{array}$ \\
\hline & & May inhibit insulin release [14]. Falls quickly when food is taken in [10]. \\
\hline \multicolumn{3}{|l|}{ Decreasing food intake } \\
\hline $\begin{array}{l}\text { Melanocortin producing hormones } \\
\text { including } \alpha-\mathrm{MSH} \text { and } \beta \text {-MSH. }\end{array}$ & HPT & $\begin{array}{l}\text { Block neurons stimulating eating behavior. Counteract NYP and AgRP }[7,10,12] \text {. } \\
\text { Stimulate cholinergic neurons in the spinal cord and thus fine-tune autonomic } \\
\text { regulation of the sympathetic and parasympathetic system [12]. } \alpha \text {-MSH is an } \\
\text { agonist for the MC4-R which regulates food intake. Regulates transcription of } \\
\text { thyrotropin-releasing hormone jointly with leptin [12]. MC4-R is a target for the } \\
\text { development of weight-reducing drugs [4•]. Involved in regulating the hypothalamo- } \\
\text { pituitary-adrenal (HPA) axis [12]. }\end{array}$ \\
\hline BDNF & HPT & $\begin{array}{l}\text { Unclear, may be stimulated by MC4-R in the ventromedial area of the HPT [15]. } \\
\text { May interact with leptin and insulin [15]. }\end{array}$ \\
\hline Insulin & PANC & $\begin{array}{l}\text { Long-acting. Facilitates uptake of glucose in body tissues such as muscles and fat } \\
\text { [10]. Promotes energy expenditure. Inhibits hypothalamic AMPK, NPY and AgRP. } \\
\text { May act synergistically with leptin }[10,16] \text {. Obesity may cause insulin resistance } \\
\text { meaning that less sugar is cleared from the blood. Insulin resistance is a matter of } \\
\text { degree rather than nature [17]. }\end{array}$ \\
\hline \multirow[t]{4}{*}{ Leptin } & \multirow[t]{4}{*}{ Mainly AT } & $\begin{array}{l}\text { Long-acting Fat sensor feeding back the amount of triglycerides to the brain by } \\
\text { acting on NPY, AgRP, melanocortin and MSH in the hypothalamus }[4 \cdot, 10,12] \text {. }\end{array}$ \\
\hline & & $\begin{array}{l}\text { If leptin levels } \uparrow \text { eating } \downarrow \text {. If leptin levels } \downarrow \text { eating } \uparrow[10] \text {. Inhibits hypothalamic } \\
\text { AMPK }[13,18] . \text { May act synergistically with insulin [16]. }\end{array}$ \\
\hline & & Regulates transcription of thyrotropin-releasing hormone jointly with MSH [12]. \\
\hline & & $\begin{array}{l}\text { Obesity may cause leptin resistance so that eating is not longer reduced when leptin } \\
\text { levels are high }[15,19 \bullet]\end{array}$ \\
\hline CKK, GLP-1, YY, PYY $3-36$, etc. & SI & $\begin{array}{l}\text { Signals a feeling of fullness and satiety }[10,19 \bullet] \text {. CKK is short acting. CKK and } \\
\text { GLP-1 may regulate meal size }[19 \bullet] \text {. }\end{array}$ \\
\hline Glucagon, amylin, etc. & PANC & Amylin may regulate meal size together with CKK and GLP-1 [19•]. \\
\hline
\end{tabular}

AT: adipose tissue; AMPK: Adenosinemonophosphate activated protein kinase; AgRP: Agouti-related peptide; BDNF: Brain-derived neurotropic factor CKK: cholecystokinin; GLP-1: glucagon-like peptide-1; HPT: hypothalamus; MC4-R, melanocortin-4 receptor; MCH: Melaninconcentrating hormone; - and $\beta$-melanocyte stimulating hormone: -MSH and $\beta$-MSH; NPY: neuropeptide Y; PYY $3-36$ Oxyntomodulinpeptide YY; PANC: pancreas; SI: Small intestine; ST: stomach

relatively low rates of anticholinergic adverse effects [25] and neither demands the use of anticholinergics to counter extrapyramidal side effects per se. This hypothesis might also not hold if we adopted the alternative view that insulin resistance and metabolic syndrome was a consequence of a disorder of the fat metabolism due to inflammation of adipose tissue rather than a consequence of a dysregulated carbohydrate metabolism [26]. 
Olanzapine and clozapine in particular are known to increase leptin [27], but as a rise in leptin is in line with the fat stores this may be a consequence rather than a cause of weight gain. High leptin levels decrease appetite but as body-own leptin targets become reset people finally becoming leptin resistant and continue to overeat despite high leptin levels. Fasting will then invariably tilt the balance toward stimulating food intake as an evolutionary bias toward weight gain [15].

The relationship between ghrelin, another potent stimulator of appetite, and SGAs appears more complex; shortterm reductions of ghrelin seem to be followed by longerterm increases [27]. Finally, SGAs linked to greater weight gain such as clozapine, olanzapine and quetiapine seem to stimulate adenosinemonophosphate activated protein kinase (AMPK) whereas risperidone, ziprasidone, haloperidol and aripiprazole do not. This AMPK stimulation is linked to H1 blockade [8] making anti-histaminergic properties a prime risk factor for weight gain.

\section{Behavioral Intervention for Control of Appetite and Weight Gain - The Evidence}

In view of the considerable impact many SGAs and even some FGAs have on the neuroendocrine system, the question arises whether or not behavioral interventions are effective in preventing or reducing weight gain. The systematic reviews and meta-analyses reviewed here seem to support this [28-34] (Table 2). Both, prevention and the treatment of weight gain, may lead to weight loss of about 3 $\mathrm{kg}$. This corresponds to a reduction of body mass index (BMI) of approximately one point. In most reviews, prevention led to slightly more weight loss than treatment $[28,29$, $31,32]$. A whole array of interventions or combination of interventions may work, including psychological interventions, diet and exercise. Psychological interventions ranged from cognitive behavioral therapy (CBT), psychoeducation, motivational interviewing to stress management. Such interventions were important but it remained unclear whether CBT or psycho-educational interventions yielded the better results [28-31]. Outpatient treatment may be superior to inpatient treatment, but tight calorie restriction in individual cases of extreme obesity may nevertheless be best conducted under inpatient conditions [33, 34]. In general, it was difficult to unravel the particular contribution of each treatment component because they tended to overlap. Programs combining all three, diet, exercise and psychological, interventions may work best [29].

Although these results are encouraging it appears that weight gain associated with to antipsychotic treatment tends to be greater than weight loss achieved through subsequent behavioral interventions $[35 \bullet, 36]$. This highlights the importance of monitoring weight and preventing weight gain in the first place. Also, significant anti-psychotic induced weight gain tends to occur early in treatment [35•-37]. Weight may then gradually increase over several years and only plateau after more than three and a half years after commencement of antipsychotics $[35 \cdot, 38,39]$. One study though, following up 113 patients who received life style advice in a group setting for 8 years, found that substantial weight loss could be achieved over long periods of time. However, this study had no control group and about $70 \%$ of the patients had dropped out of the program within two years [40].

We currently do not know whether weight loss can be sustained over longer periods of time or if in the end most patients, like the rest of the population, just re-gain weight or cycle between weight gain and weight loss [41]. Weight control measures for people taking antipsychotics are a long-term commitment to be reconciled with limited health care resources. At present, it remains unclear whether individual booster sessions could suffice to maintain the benefit. It follows that whenever possible, it would be best to opt for an antipsychotic with low weight gain liabilities rather than to rely on a behavioral intervention to control weight. Once weight gain has occurred switching to an antipsychotic with less or low weight gain liabilities also becomes an option [42-45]. Antipsychotic polypharmacy can also increase the risk [46], but the risk may depend on the combination chosen [47•].

\section{Behavioral Strategies in Light of Antipsychotic-Mediated Pharmacodynamic and Neuroendocrine Effects}

Behavioral interventions can be used to curtail antipsychotic induced weight gain. The evidence for their effectiveness in daily clinical practice remains limited though, possibly because current behavioral interventions do not have specific pharmacodynamic or neuroendocrine treatment targets. Now the question arises as to how we can augment effectiveness by using interventions specifically countering mechanisms of weight gain. From our review of factors regulating appetite, we can identify four such potential strategies:

1. Using diets which do not increase appetite to reduce craving for carbohydrates and fat.

2. Countering thirst as an anticholinergic side-effect.

3. Discouraging cannabis use.

4. Adding metformin to a behavioral intervention.

Using Diets Which Do not Increase Appetite

Successful dietary strategies depend on calorie restriction. Although it makes intuitively sense to reduce calorie intake 
Table 2 Effectiveness of behavioral interventions for appetite and weight control - evidence from systematic reviews and meta-analyses during the last ten years

\begin{tabular}{|c|c|}
\hline Study & Interventions identified as potentially successful \\
\hline Bonfioli E et al. 2012* [28] & $\begin{array}{l}\text { CBT and psycho-education, diet, exercise. Programs including } \\
\text { all three components highest impact. Similar effects in pts } \\
\text { with first episode or chronic psychosis. }\end{array}$ \\
\hline Caemmerer et al. 2012 [29] & $\begin{array}{l}\text { Nutritional and/or exercise }>\text { CBT, but effectiveness of individual } \\
\text { components difficult to judge since programs tended to overlap. } \\
\text { Effect only seen in out-patient but not in in-patient or mixed trials. }\end{array}$ \\
\hline
\end{tabular}

Gabriele et al. 2009 [30]

Alvarez-Jiminez et al. 2008 [31]

Faulkner et al. 2007 [32]

Faulkner et al. 2003 [33]

Werneke et al. 2003 [34]
T: Diet, exercise and psychological support. Increased length of intervention may lead to additional weight loss.

P: Counseling on diet and exercise may decrease the rate of weight gain but not prevent it all together.

CBT and nutritional counseling, only one study tested a diet and exercise program. Individual superior to group interventions. No significant difference between counseling and CBT, prevention and treatment, pts with recent onset of schizophrenia and chronic schizophrenia. One trial pointed towards effectiveness of prevention in pts with recent onset. OP interventions more effective than IP or mixed sample interventions.

Metformin outperformed behavioral intervention.

Metformin + behavioral intervention outperformed metformin. CBT

Weight loss difficult but not impossible. Caloric restriction, reinforcement and adjunct CBT. Caloric restriction may work best for IP. Exercise could not be evaluated.

Evidence remains limited. Calorie restriction in an IP setting, but significant deterioration of mental state can occur. Structured counseling and CBT. Life-style counseling and reinforcement.

\section{Effect size}

Pooled ES for BMI

T: $-0.86 ; 95 \%$ CI: -1.38 to -0.33

P: $-1.09 ; 95 \%$ CI: -1.51 to -0.68

TOT: -0.98 ; $95 \%$ CI: -1.31 to -0.65

Pooled ES for WGT in $\mathrm{kg}$

T: $-3.04 ; 95 \%$ CI: -4.39 to -1.68

P: -3.23 ; $95 \%$ CI: -4.41 to -2.04

Total: $-3.12 ; 95 \%$ CI: -4.03 to -2.21

Pooled ES for BMI:

TOT: -0.94 ; $95 \%$ CI: -1.45 to -0.43

ES for WGT in $\mathrm{kg}$

T: mean: -2.63 ; range: -3.20 to -.40

P: mean: 2.44 ; range: 0.37 to 4.95

Pooled ES for WGT in $\mathrm{kg}$ :

T: -2.32 ; $95 \%$ CI: -3.10 to -1.54

P: -3.05 ; $95 \%$, CI: -4.16 to -1.94

TOT: -2.56 ; $95 \%$ CI: -3.20 to -1.92

Pooled ES for BMI:

TOT: -0.91 ; $95 \%$ CI:-1.13 to -0.68

Pooled ES for WGT in kg:

T: $-1.69 ; 95 \%$ CI: -2.77 to -0.61

P: -4.87 ; 95\% CI: -7.11 to -2.64

Pooled effect sizes BMI:

T: $-0.66 ; 95 \%$ CI: -1.06 to -0.25

P: $-1.52 ; 95 \%$ CI: -2.25 to -0.79

Range WGT in kg: -28.57 to 0.4

Range (excluding case reports)

WGT in kg: -5.9 to -0.6 , but

results compared with controls

NS in most of the included studies.

CBT: cognitive behavioral therapy; m: month; ES: effect size; IP: inpatients; MA: meta-analysis; P: prevention; OP: outpatients; pt: patient; NS: not significant; SR: systematic review; T: treatment; TPT: total; WGT: weight; wk: week; y: year

*Provisional version

this may turn into an uphill struggle for patients since calorie restriction invariably leads to increased appetite. Loss of fat mass will trigger a decrease in leptin. This results in an increase of appetite in an attempt to restore the fat mass. At the same time, ghrelin levels inducing appetite may increase [19•]. In consequence, diets less likely to stimulate appetite despite energy restriction may lead to better treatment outcomes.

Patients treated with antipsychotics stimulating appetite and inducing cravings for carbohydrates and fat [48] may not be able to adhere to calorie restriction. Unless there is insight into mental illness and the subjective benefits of antipsychotic treatment are so convincing that they offset undesirable weight gain, patients are at risk of abandoning their antipsychotic treatment [49]. Indeed patients receiving such antipsychotics are faced with a paradox. On the one hand they are given drugs increasing their appetite. On the other hand they are told to decrease eating. Hence, diets not restricting calories and not increasing appetite are the obvious answer. But such diets are not easy to come by.

\section{Low Carbohydrate High Fat Diet}

The prototype of a dietary regimen not restricting calories is the low carbohydrate-high fat (LCHF), Atkins or ketogenic 
diet [50•]. The LCHF diet restricts carbohydrates but freely allows protein and fat. The LCHF is as effective as conventional diets at reducing weight and improving the lipid profile by raising "healthy" high-density lipoprotein cholesterol. Less consistently reported are reductions in blood sugar and serum triglycerides [51-56]. The LCHF diet mimics a state of starvation in that it enforces the use of ketone bodies as the result as the main energy supply. Essentially, ketone bodies, a result from the break down of free fatty acids, are used instead of glucose as obtained from carbohydrate metabolism. As carbohydrates in excess of $100 \mathrm{~g}$ per day will prevent ketosis the intake must lie below this threshold. Commonly, LCHF diets restrict carbohydrate to $30 \mathrm{~g}$ per day. Some extreme approaches only allow $10 \mathrm{~g}$.

Whether the LCHF diet works because of carbohydrate restriction remains debated. Sacks et al. have shown that targeting any of the macronutrients may promote weight loss [57]. As in most Western diets $45-50 \%$ of calories stem from carbohydrates and 35\% from fat targeting carbohydrates seems more promising. Also, it is now well known that proteins suppress appetite [58]. Notably, ketone bodies in their own right may suppress feelings of hunger; this effect may take about three days to materialize [59]. However, hunger and appetite may be suppressed right from the onset of such a diet because the gastro-intestinal peptides can still signal "fullness" in the absence of calorie restriction.

However, the LHCF diet is highly unpalatable making long- term compliance difficult. Weight regain appears most likely when people re-introduce carbohydrates and then end up on a diet which is both high in fats and carbohydrates [56], the worst of both worlds [60••]. Excessive protein intake may carry health risks but the relationship between such risks and common multifactorial diseases is complex and hence difficult to assess [61]. Recently, a large cohort study reported an increase of cardiovascular disease [62•]. The World Health Organization estimates that an intake of twice the recommended intake may be safe in "physically active individuals consuming average mixed diets who would otherwise be identified as having healthy lifestyles" [61]. Suffice it to say that many patients taking antipsychotics do not fall into this category; their safe upper level of intake could be lower. Very high protein intakes can also influence the metabolism and excretion of drugs. Finally, low carbohydrate intake may adversely affect mood and increase irritability [63]. This could limit the applicability of the LCHF in people with severe mental health problems.

\section{Other Options for Cutting Glycemic Load}

Possible -non ketogenic- alternative options to cut glycemic load include the Mediterranean or the glycemic index (GI) diet. The Mediterranean diet based on a high intake of fiber and mono-saturated fats such as olive oil, decreases glycemic load through its higher fats contents [51, 64, 65]. The GI diet reduces intake of foods with a high glycemic index (foods easily broken down to glucose). Such foods include refined - white- grain products and products in which sugar is added during processing or preparation [66]. Both dietary approaches tilt the balance from processed and highly refined to freshly prepared food irrespective of its carbohydrate and fat content.

\section{The Evidence for Carbohydrate-Reducing Diets}

Most people taking antipsychotics will have difficulties coping with diets requiring a calorie deficit. This provides a rationale for focusing on diets cutting the glycemic load especially since carbohydrate provides most of the food energy. Such specific dietary strategies have however received little attention from researchers [67].

The LCHF, the most extreme way to reduce appetite, has not been tested at all. Clinicians and researchers may believe that such diets are either too complex to follow or are detrimental to mental health. Also eating large amounts of fat to loose weight seems counter-intuitive. In practice though, most LCHF diets do not contain larger amounts of fat than normally consumed [55]; the proportion of energy derived from fat is increased because of the reduced contribution from carbohydrates. Technically, a low-carbohydrate diet should not pose a greater challenge than a low fat diet or a calorie restricted diet. Intriguingly, the ketogenic diet has occasionally been reported to improve psychotic symptoms in patients suffering from schizophrenia [68, 69]. Given that the ketogenic diet can be used to treat certain form of epilepsies such as myoclonic epilepsy [70] and may even be of value for some patients suffering from autism [71], the question arises whether this diet could be of some benefit in other neuro-developmental and degenerative brain disorders [72] including schizophrenia.

\section{Countering Thirst as an Anticholinergic Side Effect}

Some antipsychotics with high weight gain liabilities have anticholinergic effects. Thus, we can expect dry mouth with an increased urge to take fluids in compensation to occur. Notably, clozapine can cause both dry mouth and hypersalivation possibly due to differential effects at adrenergic and muscarinic receptors [73, 74]. Such effects could lead to increased salivation during sleep and rest but decreased salivation during meals [73]. Patients experiencing dry mouth often increase their fluid intake. At the same time, they may increase their calorie intake if choosing drinks containing sugar such as many sodas and fruit juices.

Unsurprisingly, sugar-sweetened sodas are a major contributor to obesity $[60 \bullet, 75 \bullet$. Fruit juices usually get better press since perceived as rich in vitamins and hence healthy, 
but juices contain a lot of sugar and as a result are quite high in calories. For example one $300 \mathrm{ml}$ glass of apple juice contains about $10 \%$ sugar providing about $114 \mathrm{kcal}$, about the same as three apples [76]. Recent trials have shown that replacing sugar-sweetened beverages by artificially sweetened drinks can indeed reduce weight gain $[77 \bullet \bullet, 78 \bullet \bullet$. However, as with so many interventions health benefits may wane over time $[78 \cdot \bullet]$.

Milk irrespective of its fat contents has not been associated with weight gain [60••]. Dairy products have a role in energy-restricted diets in helping maintaining nutritional adequacy but have no specific weight reducing properties [79॰]. Reduced fat milk and yoghurt have fewer calories but most of the nutritional value provided by full-fat milk. In the UK, dairy intake including milk has shown to be inversely associated with the consumption of sugar-sweetened drinks in low-income families [80, 81]. But ultimately fluid intakes are best met by increased water consumption. In summary, dietary counseling should include advice on how to drink well to reduce calorie-intake [56]. There is clearly a need for a randomized controlled trial in this area.

\section{Discouraging Cannabis Use}

Cannabis use is common all over the world and according to global estimates, $2.8-4.5 \%$ of the entire world population used cannabis at least once in the year 2009 [82]. Cannabis use is associated with an increased risk of psychotic illness and conversely, individuals with psychotic illness are more likely to use cannabis [82] although the estimates vary. Between, 20 and $50 \%$ of all patients with psychotic illness may consume cannabis and the trend is increasing [82-86]. As the endocannabioid system is linked to increased appetite and cannabioid receptor antagonists can induce weight loss [15] cannabis consumption will most likely potentiate antipsychotic-associated weight gain. As the prevalence of cannabis use in people suffering from psychosis is so high, the contribution of cannabis to weight gain in this population is likely to be significant. Surprisingly, this link between cannabis and weight gain remains largely ignored at present. However, one study of patients admitted to a psychiatric intensive care unit found that patients using cannabis had higher glucose levels at admission. They were also significantly more likely to gain weight during their hospital stay [87], presumably coinciding with the initiation or re-initiation of antipsychotic treatment.

\section{Adding Metformin to a Behavioral Intervention}

Metformin is a bigunanide anti-diabetic drug. Metformin is also used for the treatment of polycystic ovaries, an endocrine condition in women leading to testosterone overproduction linked to insulin resistance. Metformin activates AMPK peripherally in the liver and there prevents gluconeogenesis [10]. The absence of weight gain implies that metformin does not act on AMPK centrally in the hypothalamus. Several systematic reviews and meta-analyses have been conducted suggesting that metformin can lead to partial reversal of antipsychotic-associated weight gain and improvement of the metabolic profile [88••]. However, most trials tended to be small and of shorter duration. The emerging evidence suggested that the effect of metformin may be greatest in younger patients who receive antipsychotics for the first time and who show a tendency toward rapid weight gain and metabolic problems $[88 \bullet \bullet, 89]$. The most recent trial not yet included in any systematic review or meta-analysis was conducted in women aged between 18 and 40 years suffering from a first episode of schizophrenia and antipsychoticinduced amenorrhea. In this study, metformin was effective facilitating weight loss, improving insulin resistance and restoring menstruation [90•]. However up to date, only one study evaluated metformin head to head against a behavioral intervention. All 128 patients in this trial had experienced a first episode of schizophrenia and gained more than $10 \%$ weight after commencement of drug treatment. In this trial, metformin was superior to the behavioral intervention, but a combination of both was superior to metformin alone [91]. In consequence, early intervention with both behavioral strategies and metformin may well be indicated in people with mental illness who are about to start anti-psychotic treatment or who are undergoing treatment and have experienced significant weight gain $[92,93]$.

\section{Conclusion}

Behavioral interventions are important for the prevention and management of antipsychotic-induced weight gain, yet evidence for their efficacy remains limited. As expected, interventions to prevent weight gain seem slightly more effective than strategies to treat weight gain; weight gain, once it has occurred, is difficult to reverse fully. The results indicate that whenever possible, antipsychotics associated with weight gain should be avoided in the first place and that patients who have experienced weight gain should be offered a less offending agent. But often, this may not be feasible when patients have responded well to a particular agent and the risks and benefits for mental and physical health have to be weighed up in each individual case.

It should come as no surprise that the scope of successful behavioral interventions is limited. We find ourselves in the midst of an obesity epidemic in large parts of the industrialized world $[75 \bullet, 94]$ and weight interventions such as diet and exercise have only yielded short rather than long term 
health improvements in the general population without significant mental health problems [94]. How much less likely are people to succeed who experience acute stress or lack of drive and motivation due to a psychotic illness and who at the same time require medication increasing their appetite and weight? We already know that these patients require long-term psychological support when embarking on weight control program. Formulating specific strategies directly acting on the biochemical mechanisms of anti-psychotic induced weight gain may increase the success of behavioral programs. In our review we identified four such strategies. Of these, discouraging consumptions of sugar-sweetened drinks and cannabis are uncontroversial but continue to lack systematic study. The argument for adding metformin to a behavioral intervention is becoming more compelling particularly in young people. The ketogenic diet is certainly the most controversial approach discussed in our review. Surprisingly though there is a possibility that this diet may even yield some mental health benefits and hence be of value in selected individuals. In view of our currently rather limited treatment repertoire it seems timely systematically to explore such more specific, novel and sometimes more extreme options.

Disclosure U. Werneke: royalties from Kiener Press (KienerVerlag) to Luleå Concrete Design $\mathrm{AB}$ (of which U. Werneke is $50 \%$ owner) and payment for development of educational presentations from CPD Online (Royal College of Psychiatrists); D. Taylor: consultant to Roche, research funding from Janssen and Bristol-Myers Squibb, payment for lectures including service on speakers bureaus from Janssen and Servier, and royalties from Wiley-Blackwell; T.A.B. Sanders: member of scientific advisory panels for Global Dairy Platform and Natural Hydration Council, member of food council for Heinz, and payment for lecture from ILSI North America.

Open Access This article is distributed under the terms of the Creative Commons Attribution License which permits any use, distribution, and reproduction in any medium, provided the original author(s) and the source are credited.

\section{References}

Papers of particular interest, published recently, have been highlighted as:

- Of importance

•• Of major importance

1. Newcomer JW. Metabolic considerations in the use of antipsychotic medications: a review of recent evidence. J Clin Psychiatry. 2007;68 Suppl 1:20-7.

2. •- Falissard B, Mauri M, Shaw K, et al. The METEOR study: frequency of metabolic disorders in patients with schizophrenia. Focus on first and second generation and level of risk of antipsychotic drugs. Int Clin Psychopharmacol. 2011;26:291-302. Large multi-centric cross-sectional study challenging the concept that there is a systematic difference between first and second generation antipsychotics concerning weight gain liabilities rather than looking at individual drugs in both categories.

3. Schwarz L, Munoz R. Blood sugar levels in people treated with chlorpromazine. Am J Psychiatry. 1968;125:253-5.

4. - Lett TA, Wallace TJ, Chowdhury NI, et al. Pharmacogenetics of antipsychotic-induced weight gain: review and clinical implications. Mol Psychiatry. 2012;17:242-66. Important review highlighting the impact of pharmacogentics on neuro-endocrine factors regulating appetite and identifying potential neuroendocrine targets for drug development.

5. Baptista T, ElFakih Y, Uzcátegui E, et al. Pharmacological management of atypical antipsychotic-induced weight gain. CNS Drugs. 2008;22:477-95.

6. De Hert M, Yu W, Detraux J, et al. Body weight and metabolic adverse effects of asenapine, iloperidone, lurasidone and paliperidone in the treatment of schizophrenia and bipolar disorder: a systematic review and exploratory meta-analysis. CNS Drugs. 2012;26:733-59.

7. Reynolds GP, Kirk SL. Metabolic side effects of antipsychotic drug treatment-pharmacological mechanisms. Pharmacol Ther. 2010;125:169-79.

8. Kim SF, Huang AS, Snowman AM, et al. Antipsychotic druginduced weight gain mediated by histamine $\mathrm{H} 1$ receptor-linked activation of hypothalamic AMP-kinase. Proc Natl Acad Sci. 2007; 104:3456-9.

9. Werneke U, Taylor D, Sanders TA. Options for pharmacological management of obesity in patients treated with atypical antipsychotics. Int Clin Psychopharmacol. 2002;17:145-60.

10. Garrett RH, Grisham CM. Biochemistry, 5th edn, International edn. Pacific Grove: Brooks/Cole Cengage Learning; 2012.

11. Obuchowics E, Krysiak R, Herman ZS. Does neuropeptide Y (NPY) mediate the effects of psychotropic drugs? Neurosci Biobehav Rev. 2004;28:595-610.

12. Kishi T, Elmquist JK. Body weight is regulated by the brain: a link between feeding and emotion. Mol Psychiatry. 2005;10:132-46.

13. Kola B. Role of AMP-activated protein kinase in the control of appetite. J Neuroendocrinol. 2008;20:942-51.

14. Lim CT, Kola B, Korbonits M. The ghrelin/GOAT/GHS-R system and energy metabolism. Rev Endocr Metab Disord. 2011;12:17386.

15. Pandit R, de Jong JW, Vanderschuren LJ, Adan RA. Neurobiology of overeating and obesity: the role of melanocortins and beyond. Eur J Pharmacol. 2011;660:28-42.

16. Velloso LA, Schwartz MW. Altered hypothalamic function in dietinduced obesity. Int J Obes (Lond). 2011;35:1455-65.

17. Bremer AA, Mietus-Snyder M, Lustig RH. Toward a unifying hypothesis of metabolic syndrome. Pediatrics. 2012;129:557-70.

18. Souza RP, Tiwari AK, Chowdhury NI, et al. Association study between variants of AMP-activated protein kinase catalytic and regulatory subunit genes with antipsychotic-induced weight gain. J Psychiatr Res. 2012;46:462-8.

19. - Guyenet SJ, Schwartz MW. Regulation of food intake, energy balance, and body fat mass: implications for the pathogenesis and treatment of obesity. J Clin Endocrinol Metab. 2012;97:745-55. Comprehensive updated review of the factors driving appetite and weight gain. Challenges the often cited scientific rationale for low carbohydrate high fat diets.

20. Morton GJ, Cummings DE, Baskin DG, et al. Central nervous system control of food intake and body weight. Nature. 2006;443:289-95.

21. Bosch J, Gerstein HC, Dagenais GR, et al. n-3 fatty acids and cardiovascular outcomes in patients with dysglycemia. N Engl J Med. 2012;367:309-18.

22. Grossman SP. The role of glucose, insulin and glucagon in the regulation of food intake and body weight. Neurosci Biobehav Rev. 1986;10:295-315. 
23. Brownley KA, Heymen S, Hinderliter AL, et al. Low-glycemic load decreases postprandial insulin and glucose and increases postprandial ghrelin in white but not black women. J Nutr. 2012;142:1240-5.

24. Teff KL, Kim SF. Atypical antipsychotics and the neural regulation of food intake and peripheral metabolism. Physiol Behav. 2011;104:590-8.

25. Tollefson GD, Beasley Jr CM, Tran PV, et al. Olanzapine versus haloperidol in the treatment of schizophrenia and schizoaffective and schizophreniform disorders: results of an international collaborative trial. Am J Psychiatry. 1997;154:457-65.

26. Gustafson B, Hammarstedt A, Andersson CX, et al. Inflamed adipose tissue: a culprit underlying the metabolic syndrome and atherosclerosis. Arterioscler Thromb Vasc Biol. 2007;27:2276-83.

27. Sentissi O, Epelbaum J, Olié JP, Poirier MF. Leptin and ghrelin levels in patients with schizophrenia during different antipsychotics treatment: a review. Schizophr Bull. 2008;34:1189-99.

28. Bonfioli E, Berti L, Goss C, et al. Health promotion lifestyle interventions for weight management in psychosis: a systematic review and meta-analysis of randomised controlled trials. BMC Psychiatry. 2012;12:78.

29. Caemmerer J, Correll CU, Maayan L. Acute and maintenance effects of non-pharmacologic interventions for antipsychotic associated weight gain and metabolic abnormalities: A meta-analytic comparison of randomized controlled trials. Schizophr Res. 2012;140:159-68.

30. Gabriele JM, Dubbert PM, Reeves RR. Efficacy of behavioural interventions in managing atypical antipsychotic weight gain. Obes Rev. 2009;10:442-55.

31. Alvarez-Jiménez M, Hetrick SE, González-Blanch C, et al. Nonpharmacological management of antipsychotic-induced weight gain: systematic review and meta-analysis of randomised controlled trials. Br J Psychiatry. 2008;193:101-7.

32. Faulkner G, Cohn T, Remington G: Interventions to reduce weight gain in schizophrenia. Faulkner G, Cohn T, Remington G. Interventions to reduce weight gain in schizophrenia. Cochrane Database of Systematic Reviews. 2007. Issue 1. Art. No.: CD005148. doi: 10.1002/14651858.CD005148.pub2.

33. Faulkner G, Soundy AA, Lloyd K. Schizophrenia and weight management: a systematic review of interventions to control weight. Acta Psychiatr Scand. 2003;108:324-32.

34. Werneke U, Taylor D, Sanders TA, Wessely S. Behavioural management of antipsychotic-induced weight gain: a review. Acta Psychiatr Scand. 2003;108:252-9.

35. • Bushe CJ, Slooff CJ, Haddad PM, Karagianis JL. Weight change from 3-year observational data: findings from the worldwide schizophrenia outpatient health outcomes database. J Clin Psychiatry. 2012;73:e749-55. Latest available update on the pattern of weight gain over time for various antipsychotics.

36. Tardieu S, Micallef J, Gentile S, Blin O. Weight gain profiles of new anti-psychotics: public health consequences. Obes Rev. 2003:4:129-38.

37. Tarricone I, Ferrari Gozzi B, Serretti A, Grieco D, et al.: Weight gain in antipsychotic-naive patients: a review and meta-analysis. Psychol Med. 2010;187-200.

38. Bai YM, Chen JY, Chen TT, et al. Weight gain with clozapine: 8year cohort naturalistic study among hospitalized Chinese schizophrenia patients. Schizophr Res. 2009;108:122-6.

39. Henderson DC, Cagliero E, Gray C, et al. Clozapine, diabetes mellitus, weight gain, and lipid abnormalities: A five-year naturalistic study. Am J Psychiatry. 2000;157:975-81.

40. Holt RI, Pendlebury J, Wildgust HJ, et al. Intentional weight loss in overweight and obese patients with severe mental illness: 8-year experience of a behavioral treatment program. J Clin Psychiatry. 2010;71:800-5.

41. Alvarez-Jiménez M, Martínez-García O, Pérez-Iglesias R, et al. Prevention of antipsychotic-induced weight gain with early behavioural intervention in first-episode psychosis: 2-year results of a randomized controlled trial. Schizophr Res. 2010;116:16-9.

42. Ganguli R, Brar JS, Garbut R, Chang CC, et al. Changes in weight and other metabolic indicators in persons with schizophrenia following a switch to aripiprazole. Clin Schizophr Relat Psychoses. 2011;5:75-9.

43. Karayal ON, Glue $P$, Bachinsky M, et al. Switching from quetiapine to ziprasidone: a sixteen-week, open-label, multicenter study evaluating the effectiveness and safety of ziprasidone in outpatient subjects with schizophrenia or schizoaffective disorder. J Psychiatr Pract. 2011;17:100-9.

44. Barak Y, Aizenberg D. Switching to aripiprazole as a strategy for weight reduction: a meta-analysis in patients suffering from schizophrenia. J Obes. 2011;pii: 898013.

45. Mukundan A, Faulkner G, Cohn T, Remington G: Antipsychotic switching for people with schizophrenia who have neurolepticinduced weight or metabolic problems. Cochrane Database Systematic Reviews. 2010. Issue 12. Art. No.: CD006629. doi: 10.1002/14651858.CD006629.pub2.

46. Taylor D, Young C, Esop R, et al. Testing for diabetes in hospitalised patients prescribed antipsychotic drugs. $\mathrm{Br} \mathrm{J}$ Psychiatry. 2004;85:152-6.

47. - Gallego JA, Nielsen J, De H, et al. Safety and tolerability of antipsychotic polypharmacy. Expert Opin Drug Saf. 2012;11:52742. A timely reminder of the risks associated with antipsychotic polypharmacy.

48. Zimmermann U, Kraus T, Himmerich H, et al. Epidemiology, implications and mechanisms underlying drug-induced weight gain in psychiatric patients. J Psychiatr Res. 2003;37:193-220.

49. Lieberman JA, Stroup TS, McEvoy JP, et al. Effectiveness of antipsychotic drugs in patients with chronic schizophrenia. N Engl J Med. 2005;353:1209-23.

50. - Hite AH, Berkowitz VG, Berkowitz K. Low-carbohydrate diet review: shifting the paradigm. Nutr Clin Pract. 2011;26:300-8. Challenging the notion that low-carbohydrate high fat diets may be dangerous which though intuitively appealing has as yet not been proven.

51. Shai I, Schwarzfuchs D, Henkin Y, et al. Weight loss with a lowcarbohydrate, Mediterranean, or low-fat diet. N Engl J Med. 2008;359:229-41.

52. Gardner CD, Kiazand A, Alhassan S, et al. Comparison of the Atkins, Zone, Ornish, and LEARN diets for change in weight and related risk factors among overweight premenopausal women: the A TO Z Weight Loss Study: a randomized trial. JAMA. 2007;297:969-77.

53. Morgan LM, Griffin BA, Millward DJ, et al. Comparison of the effects of four commercially available weight-loss programmes on lipid-based cardiovascular risk factors. Public Health Nutr. 2009;12:799-807.

54. Truby H, Baic S, deLooy A, et al. Randomised controlled trial of four commercial weight loss programmes in the UK: initial findings from the BBC "diet trials". BMJ. 2006;332:1309-14.

55. Dansinger ML, Gleason JA, Griffith JL, et al. Comparison of the Atkins, Ornish, Weight Watchers, and Zone diets for weight loss and heart disease risk reduction: a randomized trial. JAMA. 2005;293:43-53.

56. Werneke U: Weight or shape. Finding your way to diet and exercise [working title]. München: Kiener Verlag, (in press).

57. Sacks FM, Bray GA, Carey VJ, et al. Comparison of weight-loss diets with different compositions of fat, protein, and carbohydrates. N Engl J Med. 2009;360:859-73.

58. Mithieux G, Misery P, Magnan C, et al. Portal sensing of intestinal gluconeogenesis is a mechanistic link in the diminution of food intake induced by diet protein. Cell Metab. 2005;2:321-9.

59. Veech RL. The therapeutic implications of ketone bodies: the effects of ketone bodies in pathological conditions: ketosis, 
ketogenic diet, redox states, insulin resistance, and mitochondrial metabolism. Prostaglandins Leukot Essent Fatty Acids. 2004;70:309-19.

60. - Mozaffarian D, Hao T, Rimm EB, et al. Changes in diet and lifestyle and long-term weight gain in women and men. $\mathrm{N}$ Engl J Med. 2011;364:2392-404. A huge prospective survey from the US identifying foods and behaviours making us put on weight.

61. World Health Organization: Protein and amino acids requirement in human nutrition. WHO Technical Report Series 935. Available at http://whqlibdoc.who.int/trs/WHO_TRS_935_eng.pdf. Accessed October 2012.

62. - Lagiou P, Sandin S, Lof M, et al. Low carbohydrate-high protein diet and incidence of cardiovascular diseases in Swedish women: prospective cohort study. BMJ. 2012;344:e4026. A timely reminder that the debate about potential health risks of the LCHF diet remains open.

63. Brinkworth GD, Buckley JD, Noakes M, et al. Long-term effects of a very low-carbohydrate diet and a low-fat diet on mood and cognitive function. Arch Intern Med. 2009;169:1873-180.

64. Nordmann AJ, Suter-Zimmermann K, Bucher HC, et al. Metaanalysis comparing Mediterranean to low-fat diets for modification of cardiovascular risk factors. Am J Med. 2011;124:841-851.e2.

65. Kastorini CM, Milionis HJ, Goudevenos JA, Panagiotakos DB. Mediterranean diet and coronary heart disease: is obesity a link? A systematic review. Nutr Metab Cardiovasc Dis. 2010;20:536-51.

66. Thomas D, Elliott EJ, Baur L: Low glycaemic index or low glycaemic load diets for overweight and obesity. CochraneDatabase of Systematic Reviews. 2007. Issue 3. Art. No.: CD005105. doi: 10.1002/14651858.CD005105.pub2.

67. Skouroliakou M, Giannopoulou I, Kostara C, et al. Effects of nutritional intervention on body weight and body composition of obese psychiatric patients taking olanzapine. Nutrition. 2009;25:729-35.

68. Kraft BD, Westman EC. Schizophrenia, gluten, and lowcarbohydrate, ketogenic diets: a case report and review of the literature. Nutr Metab (Lond). 2009;6:10.

69. Pancheco A, Easterling WS, Preyer MW. A pilot study of the ketogenic study in schizophrenia. Am J Psychiatry. 1965;121:1110-1.

70. Nangia S, Caraballo RH, Kang HC, et al. Is the ketogenic diet effective in specific epilepsy syndromes? Epilepsy Res. 2012;100:252-7.

71. Evangeliou A, Vlachonikolis I, Mihailidou H, et al. Application of a ketogenic diet in children with autistic behavior: pilot study. J Child Neurol. 2003;18:113-8.

72. Stafstrom CE, Rho JM. The ketogenic diet as a treatment paradigm for diverse neurological disorders. Front Pharmacol. 2012;3:59.

73. Ekström J, Godoy T, Riva A. Clozapine: agonistic and antagonistic salivary secretory actions. J Dent Res. 2010;89:276-80.

74. Syed Sheriff RJ, Au K, Cahill C, et al. Pharmacological interventions for clozapine-induced hypersalivation. Schizophr Bull. 2008;34:611-2.

75. - Lustig RH, Schmidt LA, Brindis CD. Public health: The toxic truth about sugar. Nature. 2012;482:27-9. A controversial but important feature which shows how sugar has gradually increased in our diet to replace fat as the number one risk factor for obesity.

76. Werneke U for The Royal College of Psychiatrists: Eating well. Available at http://www.rcpsych.ac.uk/mentalhealthinfo/problems/ nutrition.aspx. Accessed August 2012.

77. •- De Ruyter JC, Olthof MR, Seidell JC, Katan MB. A trial of sugar-free or sugar-sweetened beverages and body weight in children. N Engl J Med. 2012;367:1397-406. An important trial showing that replacing sugar-sweetened sodas with artificially sweetened sodas can reduce weight gain.

78. •• Ebbeling CB, Feldman HA, Chomitz VR, et al. A randomized trial of sugar-sweetened beverages and adolescent body weight. $\mathrm{N}$ Engl J Med. 2012;367:1407-16. Yet another trial showing that a simple solitary intervention may be of some benefit, but also a reminder that health benefits may wane over time.

79. • Chen M, Pan A, Malik VS, Hu FB. Effects of dairy intake on body weight and fat: a meta-analysis of randomized controlled trials. Am J Clin Nutr. 2012;96:735-47. Counters a common misconception that intake of dairy products may lead to weight gain.

80. Sanders TA. Role of dairy foods in weight management. Am J Clin Nutr. 2012;96:687-8.

81. Holmes BA, Kaffa N, Campbell K, Sanders TA. The contribution of breakfast cereals to the nutritional intake of the materially deprived UK population. Eur J Clin Nutr. 2012;66:10-7.

82. Degenhardt L, Hall W. Extent of illicit drug use and dependence, and their contribution to the global burden of disease. Lancet. 2012;379:55-70.

83. Moore E, Mancuso SG, Slade T, et al. The impact of alcohol and illicit drugs on people with psychosis: The second Australian national survey of psychosis. Aust N Z J Psychiatry. 2012;46:864-78.

84. Kivimies K, Repo-Tiihonen E, Tiihonen J. The substance use among forensic psychiatric patients. Am J Drug Alcohol Abuse. 2012;38:273-7.

85. Koskinen J, Löhönen J, Koponen H, Isohanni M, et al. Rate of cannabis use disorders in clinical samples of patients with schizophrenia: a meta-analysis. Schizophr Bull. 2010;36:1115-30.

86. Green B, Young R, Kavanagh D. Cannabis use and misuse prevalence among people with psychosis. $\mathrm{Br} \mathrm{J}$ Psychiatry. 2005; 187:306-13.

87. Isaac M, Isaac M, Holloway F. Is cannabis an anti-antipsychotic? The experience in psychiatric intensive care. Hum Psychopharmacol. 2005;20:207-10.

88. • Newall H, Myles N, Ward PB, et al. Efficacy of metformin for prevention of weight gain in psychiatric populations: a review. Int Clin Psychopharmacol. 2012;27:69-75. An important reminder that psychiatrists should consider metformin early rather than late if behavioural interventions for antipsychotic associated weight gain do not work. Adding metformin may make a difference particularly for young people.

89. Hasnain M, Fredrickson SK, Vieweg WV. Metformin for obesity and glucose dysregulation in patients with schizophrenia receiving antipsychotic drugs. J Psychopharmacol. 2011;25:715-21.

90. - Wu RR, Jin H, Gao K, et al. Metformin for treatment of antipsychotic-induced amenorrhea and weight gain in women with first-episode schizophrenia: a double-blind, randomized, placebocontrolled study. Am J Psychiatry. 2012;169:813-21. More trial evidence for the benefits of metformin, particularly in female patients.

91. Wu RR, Zhao JP, Jin H, et al. Lifestyle intervention and metformin for treatment of antipsychotic-induced weight gain: a randomized controlled trial. JAMA. 2008;299:185-93.

92. Curtis J, Newall H, Myles N, Shiers D, Samaras K. Considering metformin in cardiometabolic protection in psychosis. Acya Psychiatr Scand. 2012;126:302-3.

93. Taylor D. Metformin for schizophrenia. Acta Psychiatr Scand. 2012;126:233-4.

94. Mann T, Tomiyama AJ, Westling E, et al. Medicare's search for effective obesity treatments: diets are not the answer. Am Psychol. 2007;62:220-33. 